\title{
A EVOLUÇÃO DAS FEIÇÕES EROSIVAS DA BACIA DO CÓRREGO ESPRAIADO, SÃO PEDRO (SP)
}

\author{
THE EVOLUTION OF EROSION FEATURES \\ IN THE ESPRAIADO BASIN, SÃO PEDRO (SP) \\ ÉVOLUTION DES CARACTÉRISTIQUES ÉROSIVES \\ DU BASSIN-VERSANT DU RUISSEAU ESPRAIADO, SÃO PEDRO (SP) \\ Evandro Daniel - Universidade de São Paulo - São Paulo - São Paulo - Brasil \\ evandrogeo@yahoo.com.br \\ Bianca Carvalho Vieira - Universidade de São Paulo - São Paulo - São Paulo - Brasil \\ biancacv@usp.br
}

\begin{abstract}
Resumo
Na década de 1980 foram estimadas cerca de 3.000 voçorocas no estado de São Paulo, e aproximadamente $80 \%$ das terras cultiváveis tinham processos erosivos, ultrapassando o limite de recuperação natural. Uma perda anual de aproximadamente 200 milhões de toneladas de solo. Desta forma, o objetivo deste trabalho foi identificar e avaliar a evolução das feições erosivas na bacia do córrego Espraiado no município de São Pedro (SP) entre os anos de 1962 e 2006. Para tal, as feições erosivas foram mapeadas nestes cenários (1962 e 2006) usando ortofotos, verificações em campo e o cálculo do volume de perda de solo. Os resultados mostraram uma redução de $76 \%$ entre 1962 e 2006 . A maior perda de solo foi identificada em 1962, 4.410.000 $\mathrm{m}^{3}$, ou seja, 300\% maior do que em $2006\left(1.428 .000 \mathrm{~m}^{3}\right)$. Em ambos os cenários, as feições erosivas foram identificadas na alta e média bacia. Assim, usando ortofotos mais precisas foi possível identificar importantes mudanças na distribuição espacial das erosões e no volume total de perda de solo.
\end{abstract}

Palavras-chave: feições erosivas, São Pedro, SIG.

\section{Abstract}

In the 1980s it was estimated the occurrence of 3,000 gullies erosion in the state of São Paulo, and around $80 \%$ of crops fields had erosion processes that exceeded the natural recuperation limit. An annual loss reaching about 200 million tons of soil. Thus, the goal of this paper was to identify and evaluate the evolution of erosive features in the córrego Espraiado basin in the municipality of São Pedro (SP) between the years 1962 and 2006. For that, the erosion features were mapped in these scenarios (1962 and 2006) using orthophotos and field trips were carried out to check all the features and to calculate the volume of soil loss. The results shows a $76 \%$ of decrease between 1962 and 2006. The highest soil loss was identified in $1962,4.410 .000 \mathrm{~m}^{3}$, in other words, $300 \%$ higher than 2006 scenario $\left(1.428 .000 \mathrm{~m}^{3}\right)$. On both scenarios, the erosion features were located in high and middle levels of the basin. Therefore, using more accurate orthophotos it was possible to identify important changes in the spatial distribution of erosion features and in the total volume in of soil loss.

Key words: erosion features, São Pedro, GIS.

\section{Résumé}

Aux années 1980, on éstimait 3.000 ravinements à l'état de São Paulo, et environ $80 \%$ des terres arables souffraient de processus érosifs, excédant les limites de récupération naturelle. Une perte annuelle d'environ 200 millions de tonnes de sol. Ainsi, lrobjectif de cette étude a été diévaluer liévolution des caractéristiques érosives du bassin-versant du ruisseau Espraiado, São Pedro (SP) entre les années 1962 et 2006 . Pour atteindre cet objectif, les caractéristiques érosives ont été cartographiées en deux scénarios (1962 et 2006), à travers d`orthophotos, de vérifications de terrain et du calcul du volume de perte de sol. Les résultats ont démontré une 
réduction de $76 \%$ entre 1962 et 2006. La plus grande perte de sol a été identifiée en $1962,4.410 .000 \mathrm{~m}^{3}$, soit $300 \%$ supérieure qu'en $2006\left(1.428 .000 \mathrm{~m}^{3}\right)$. Aux deux scénarios, les caractéristiques érosives étaient situ sur le haut et le moyen bassin. Ainsi, parmi d'orthophotos plus précises, nous avons pu identifier des transformations importantes sur la distribution spatiale de l'érosion et sur le volume total de perte de sol.

Mots-clés: caractéristiques érosives, São Pedro, SIG.

Introdução

Os processos erosivos são considerados indícios de instabilidade dos sistemas geomorfológicos, uma vez que o equilíbrio de um sistema representa o ajustamento completo das suas variáveis internas às condições externas, e uma ruptura do equilíbrio pode desencadear uma readaptação (Christofoletti, 1980). Mundialmente o tema também se destaca, atraindo à atenção de pesquisadores de diversas áreas, conforme explica Montgomery (2008). O autor realizou uma extensa pesquisa sobre a utilização do solo para fins agrícolas, evidenciando que as práticas que permitiram perdas excessivas do solo, levaram grupos humanos, ao longo da história, ao colapso. Como exemplo, o autor associa o declínio da civilização Suméria à continuidade de processos erosivos atuantes sobre áreas agrícolas, comprometendo o abastecimento de alimentos.

A formação de feições erosivas apresenta comportamento diferenciado de acordo com a fisiografia da paisagem de cada região. Ao mudar as dimensões do tempo e do espaço, também mudam as relações múltiplas causais e o sistema morfogenético precisa ser reconsiderado (Cruz, 1985). As principais causas podem estar relacionadas aos fatores antrópicos (ex. uso e manejo do solo), às mudanças climáticas, à litologia, ao relevo, à vegetação e aos parâmetros morfométricos das encostas. Estes últimos influenciam na origem e no desenvolvimento das feições no espaço e no tempo (Brady, 1989; Goudie, 1990; Torri, 1996; Sidorchuk, 1999, Tamene; Vlek, 2007, Kuhnet et al., 2010, entre outros). Entretanto, a erosão é um processo relacionado à escala geológica (Riser, 1995), se tornando mais evidente devido ao início da prática da agricultura, à intensificação do uso da terra e à perda de solos (Bertoni; Lombardi Neto, 1985; Braimoh; Vlek, 2007). Assim, foi a partir do início do século XIX, que se iniciam os primeiros relatos, registros e estudos sobre a ocorrência de diversas formas de feições erosivas lineares aceleradas no estado de São Paulo (Mauro, 1989).

Para aprimorar o mapeamento e o estudo dos processos erosivos, as ferramentas tecnológicas têm sido muito utilizadas, sobretudo para integração de dados georreferenciados, elaboração de mapas temáticos, 
diagnóstico ambiental, avaliação e prognósticos ambientais (Câmara; Medeiros, 2001). As informações podem ser capturadas, armazenadas e analisadas, combinando dados espaciais de diversas fontes em uma base unificada e representar os diferentes fenômenos espaciais por meio da sobreposição de uma série de planos de informação (Veiga; Silva, 2004). Coltrinari (2000) destaca também que a integração de pesquisas mediante a adoção de técnicas e de linguagens especializadas possibilita a reflexão conjunta e a produção de resultados integrados, contribuindo para o avanço do entendimento dos processos geomorfológicos.

Na década de 1980 estimava-se a existência de 3.000 voçorocas no estado de São Paulo, e aproximadamente $80 \%$ das terras cultiváveis sofriam processos erosivos, além dos limites de recuperação natural do solo, representando uma perda anual de aproximadamente 200 milhões de toneladas de solo. O custo para a correção e para estabilização dessas voçorocas seria de aproximadamente $20 \%$ do orçamento do Estado naquele período. Neste contexto no município de São Pedro em função da grande concentração de erosão, foi considerado com alta ocorrência do processo no estado de São Paulo (Daee, 1989; Kertzman et al., 1995; Santoro; Fúlfaro, 1996, entre outros). De forma geral as feições erosivas no município apresentam taludes profundos e acentuados, geometrias mais retilíneas e são geralmente de grandes dimensões (Figura 1), estando presentes em

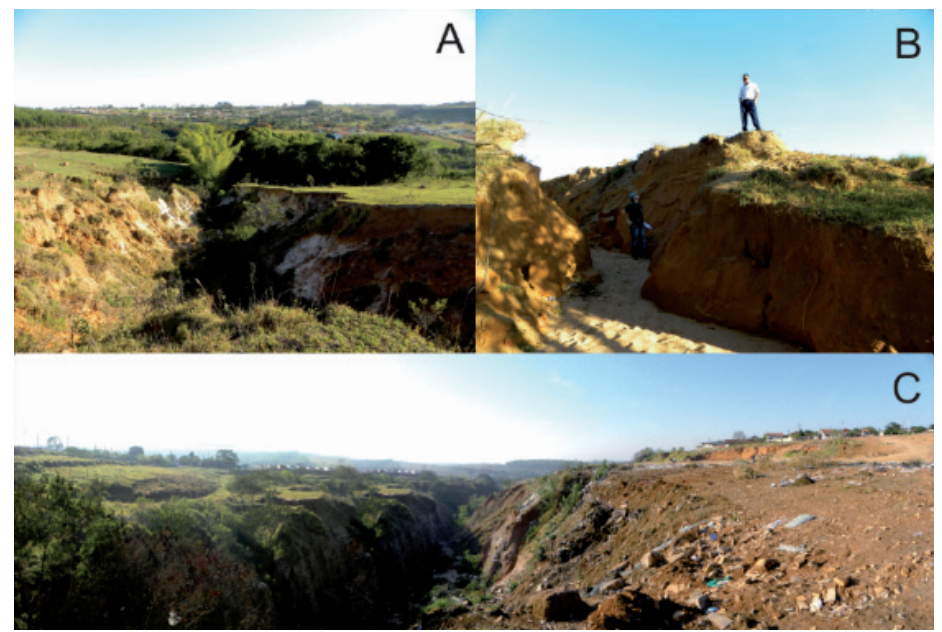

Figura 1 - (A) Voçoroca em área de pastagem, silvicultura e próxima aos loteamentos urbanos.

(B) Detalhe de uma das feições com taludes acentuados, fundo plano com sedimento arenoso $\mathrm{e}$ vegetação rasteira. (C) Vista de uma voçoroca de grande dimensão utilizada como depósito de lixo. 
áreas agrícolas, em pastagens e em áreas urbanas, onde algumas são utilizadas como depósito de resíduos sólidos. Desta forma, o objetivo deste trabalho foi identificar e avaliar a evolução (ex. área) das feições erosivas na bacia do córrego Espraiado no município de São Pedro (SP) nos anos de 1962 e 2006.

\section{Área de estudo}

A bacia do córrego Espraiado (área de $8 \mathrm{~km}^{2}$ ) está localizada a nordeste do município de São Pedro (SP) com suas cabeceiras de drenagem ao norte (NW-SE) e o seu canal principal desaguando no ribeirão Araquá, afluente do rio Piracicaba (Figura 2).

Bósio (1973) caracterizou a geologia da área de São Pedro por meio de trabalhos de campo, ensaios de laboratório e ferramentas estatísticas. O autor concluiu que a formação Botucatu na área subdivide-se em duas fácies individualizáveis: uma inferior, denominada Pirambóia e a outra, superior, chamado Botucatu; depósitos lacustres são raros dentro da sequência eólica; a incidência de minerais pesados na Formação Botucatu é inferior a $1 \%$, sendo normal ao redor de $0,5 \%$; o fenômeno da silicificação que ocorre no conglomerado Itaqueri e nos arenitos da fácies Botucatu acha-se correlacionada com o intemperismo de rochas básicas, entre outros.

Geomorfologicamente, o município está situado na Zona de Circundesnudação Periférica, compartimento topográfico de origem denudacional, largamente embutido entre as áreas serranas elevadas e acidentadas (750 e $1600 \mathrm{~m}$ ) e as escarpas e festões das altas cuestas basálticas (Figura 3) entre 850m e 1100m (Ab’Saber, 1949). Predominam na área Argissolos e de Latossolos Vermelho-Amarelos, que podem atingir, em média, uma espessura entre 15 e $20 \mathrm{~m}$. A maior parte possui horizonte subsuperficial arenoso e espesso e um elevado teor de acidez (Sanchez, 1971; Silva, 1993; Santoro; Fúlfaro, 1996; Embrapa, 2013). Sobre o assunto, Alarsa (1994) realizou uma descrição e uma caracterização da distribuição da cobertura pedológica e sua associação com as formas do relevo do interflúvio dos ribeirões Araquá e Samambaia, numa escala de semi-detalhe (1:25.000). A autora identificou uma evolução dos graus de dissecação de norte para sul, cuja intensidade encontra-se na faixa oriental (ribeirão Araquá) e que os sistemas podzólicos acompanham este processo. 
Em grande parte da bacia a vegetação original, mata latifoliada, foi substituída por pastagens, cana-de-açúcar, culturas anuais e reflorestamento (eucalipto), com resquícios nas áreas de drenagem e na parte superior de algumas encostas (Zuquette; Carvalho; Yamanouth, 2007).
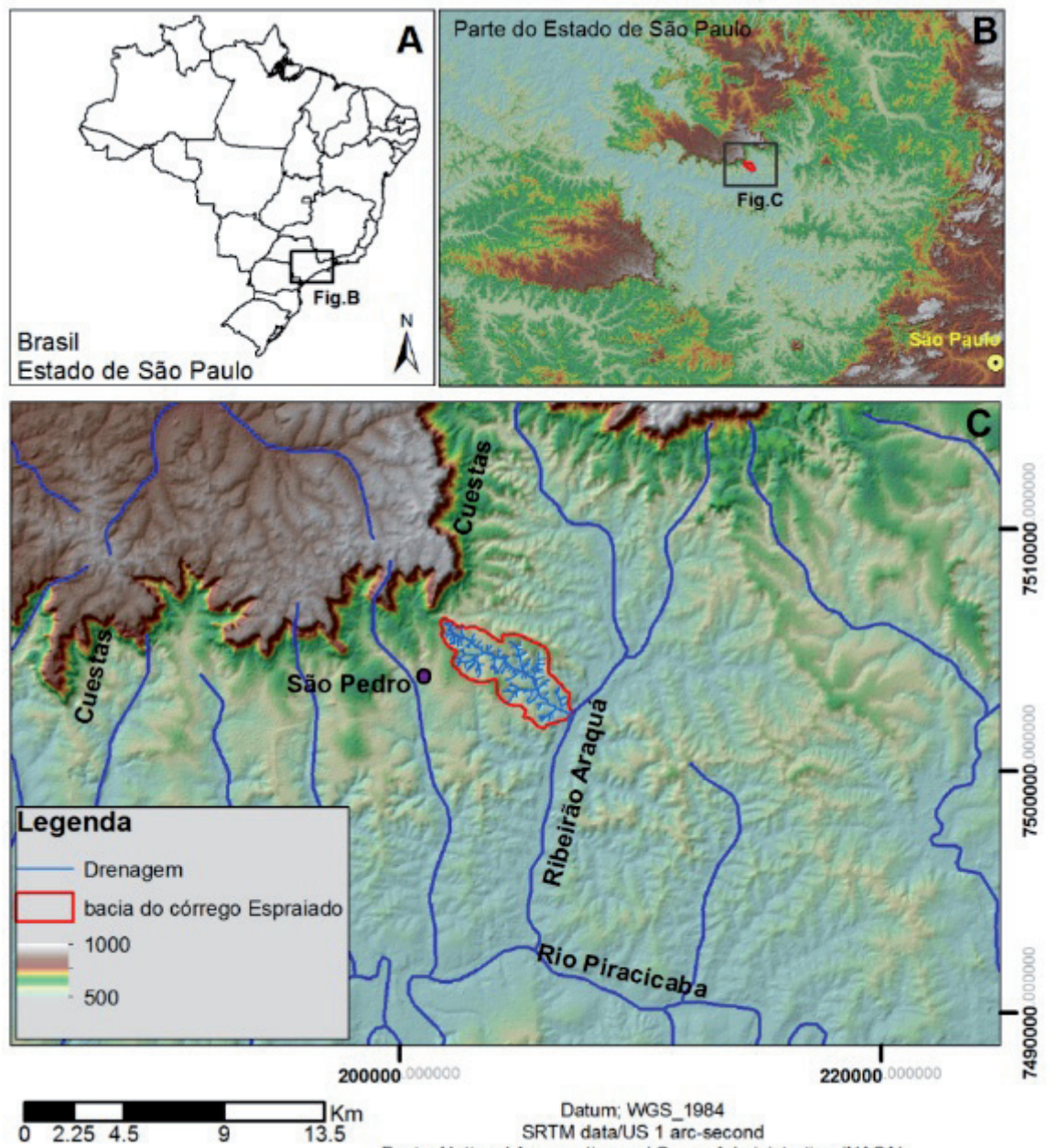

Datum; WGS_1984

SRTM data'US 1 arc-second

Fonte: National Aeronautics and Space Administration (NASA)

Figura 2: Localização da área de estudo. (A) Localização do estado de São Paulo. (B) Localização da Bacia no território paulista (em vermelho). (C) Detalhe da bacia em relação ao limite das cuestas, à cidade de São Pedro e ao rio Piracicaba. 


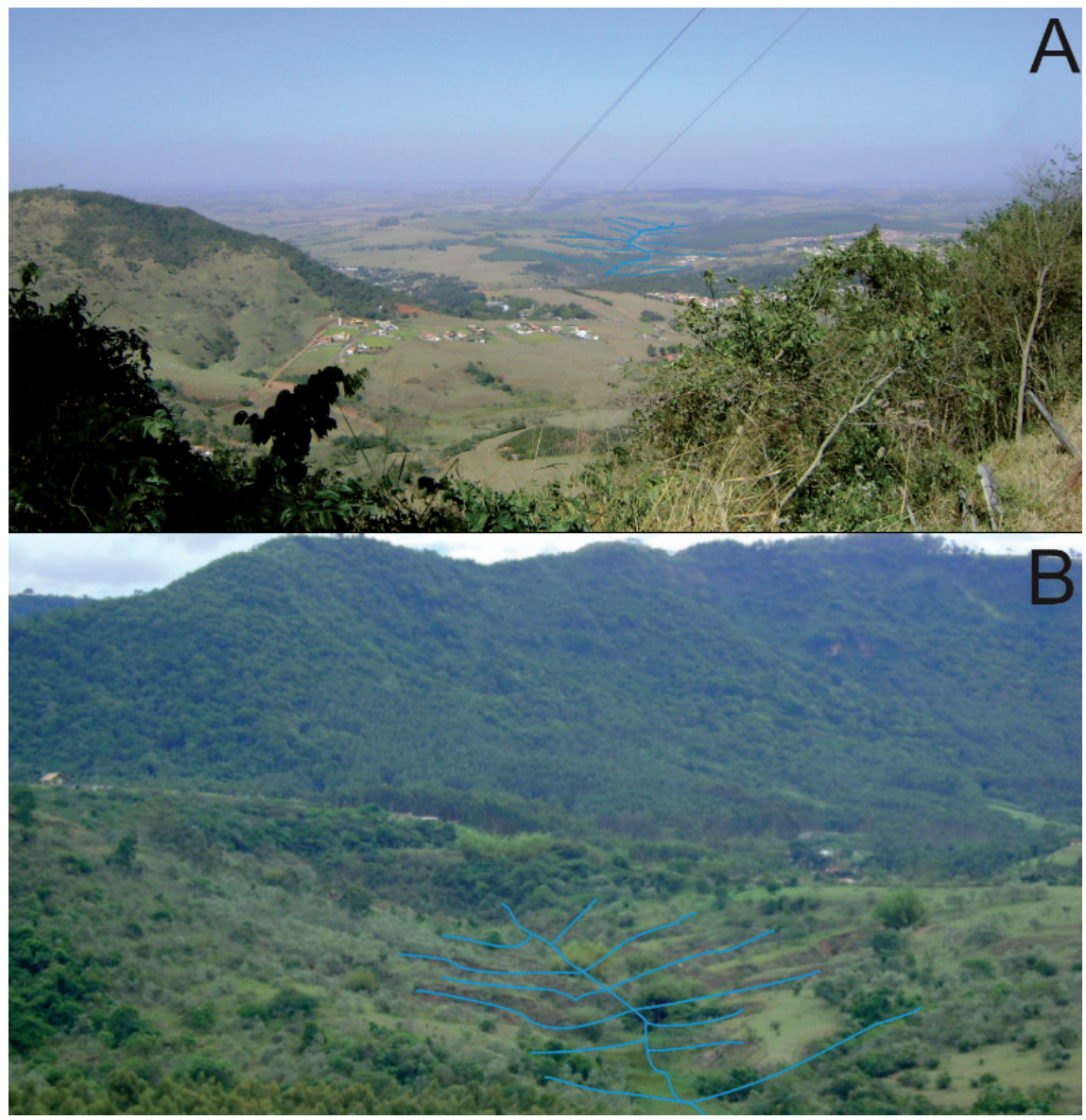

Figura 3 - (A) Vista da bacia do córrego Espraiado em direção ao front da Cuesta e (B) a partir do front da Cuesta. Algumas drenagens da bacia estão destacadas pelas linhas.

\section{Materiais e métodos}

Foram construídos mapas de feições erosivas dos anos de1962 e de 2006, utilizando ortofotos ${ }^{1}$ em escalas 1:25.000 (cenário 1962) e 1:30.000 (cenário 2006), validadas pelo Plano de Exatidão Cartográfica (PEC). O mapeamento seguiu os seguintes critérios visuais: sombreamento, solo exposto, entalhamento do relevo, fissuras no solo e declividade acentuada (Figura 4). 


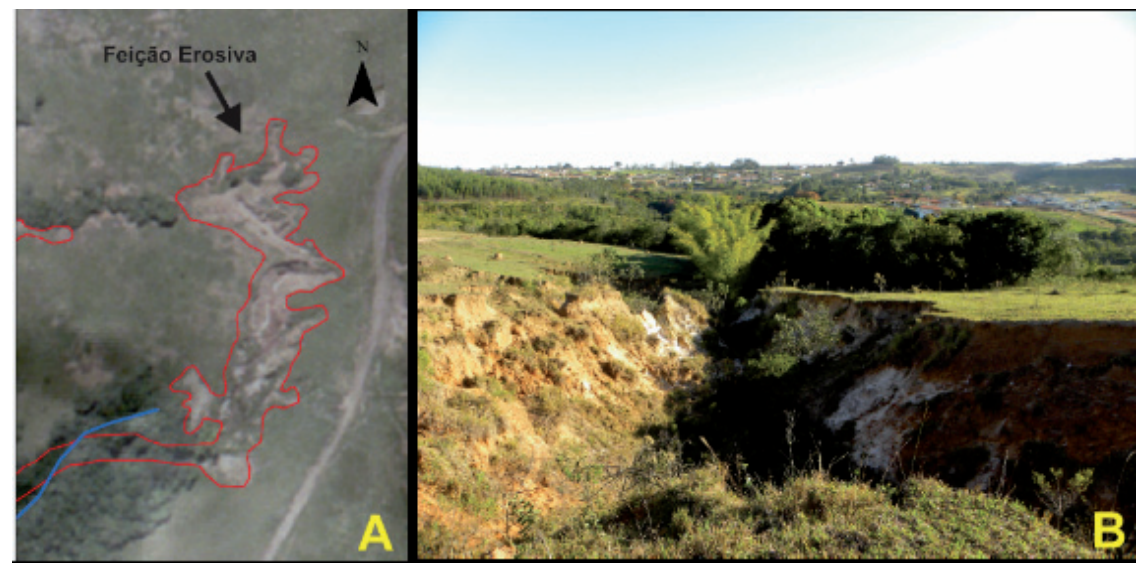

Figura 4 - (A) Trecho do mapa de feições erosivas (polígono destacado) (Figura sem escala). (B) Validação in loco das características das feições, 2013.

Na sequência foi criado um layer para cada cenário, por meio do programa Arc Catalog 9.3.1 (Arcgis 9.3.1), especificamente para as feições erosivas mapeadas e delimitadas por polígonos. Posteriormente foi feita uma comparação entre os dois cenários e a caracterização da evolução e da distribuição das feições com o auxílio da ferramenta Calculate Geometrydo Arcgis 9.3.1. O mapa das feições erosivas do cenário 2006 foi atualizado por meio de trabalhos de campo com identificação de 90\% das feições erosivas, utilizando-se uma ficha de cadastro baseada nos trabalhos de Mendonça, Guerra e Mendes (2001) e Macedo et al. (2004) (Figura 5).

Também foram selecionadas nove feições erosivas, pelos seguintes critérios: formato ramificado, acesso, localização em formas côncavas e alta declividade, as quais foram realizadas 27 medidas de profundidade em diferentes setores das mesmas e obtida uma média ponderada (Figura 6). Tal valor foi utilizado para o cálculo de perda de solo em volume $\left(\mathrm{m}^{3}\right)$ de cada feição mapeada nos dois cenários (1962 e 2006). 


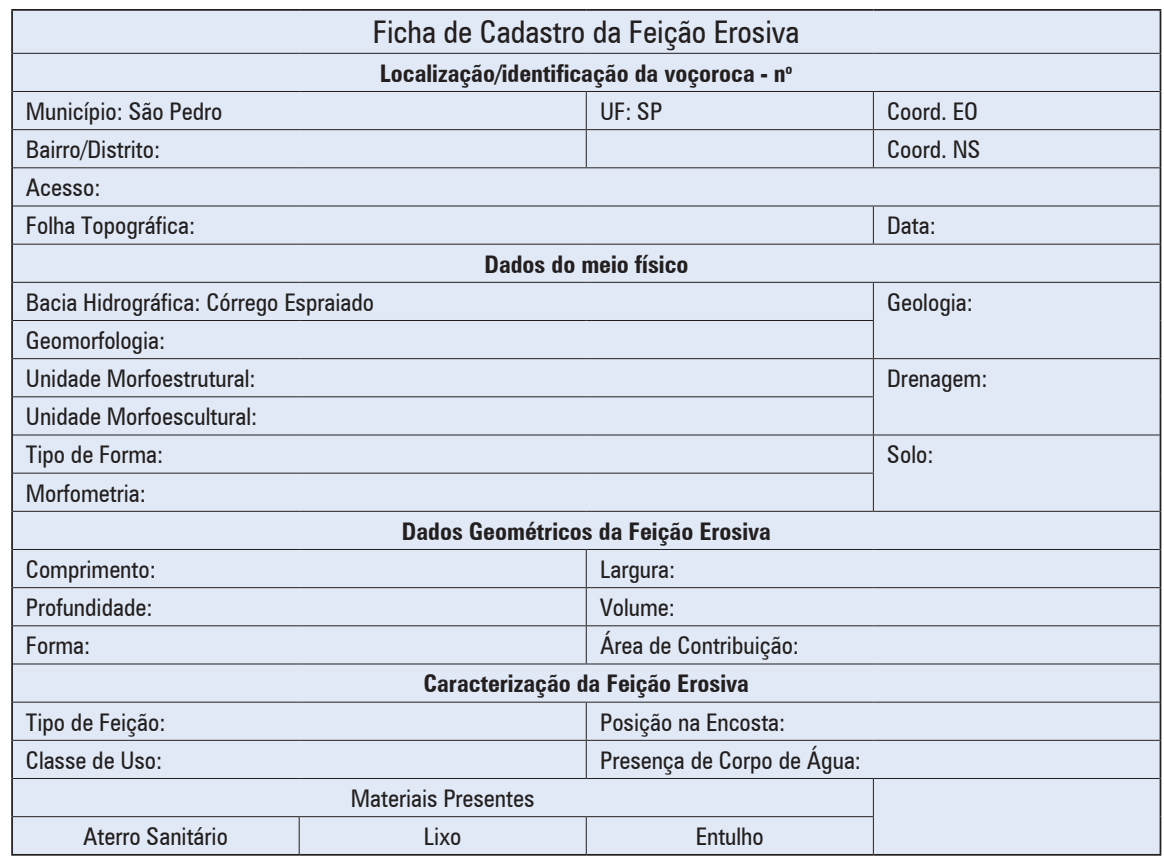

Figura 5 - Modelo de Cadastro de Feição Erosiva utilizado no trabalho de campo.

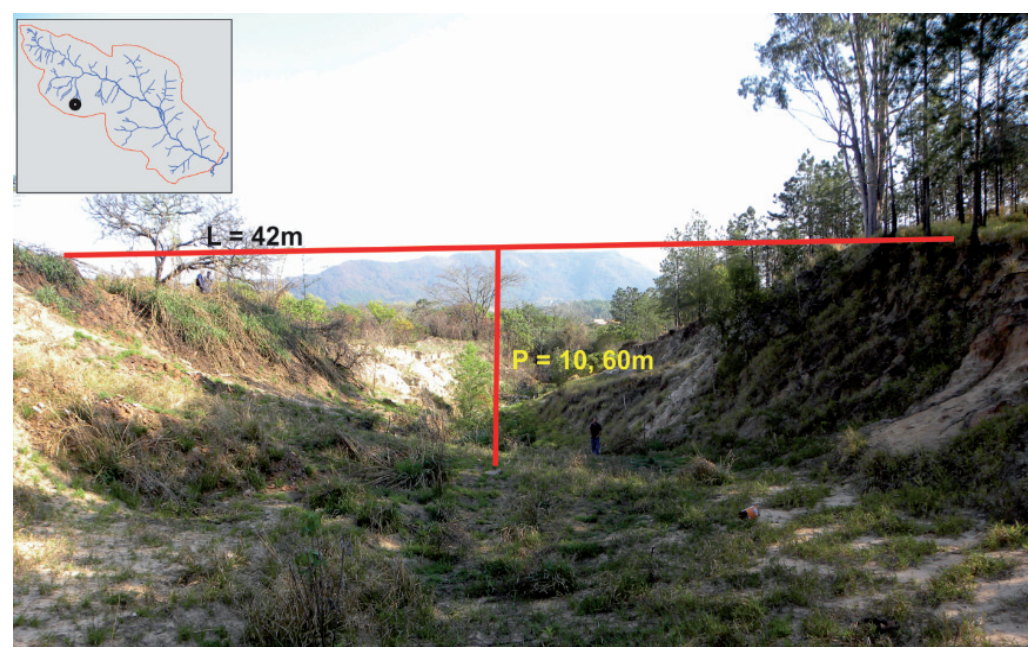

Figura 6 - Vista da voçoroca, a partir do seu interior, com as medidas realizadas em campo, $\mathrm{L}=$ largura $(42 \mathrm{~m})$ e $\mathrm{P}=$ profundidade $(10,60 \mathrm{~m})$. Ano: 2013. 
Resultados e discussões

Área, número e volume das feições

Comparando os mapas dos cenários 1962 e 2006 verificou-se uma redução de $76 \%$ das feições erosivas. No primeiro cenário (Figura 7), foram mapeadas 86 feições, equivalentes a $0,45 \mathrm{~km}^{2}$ (3,75\% da área total) e apenas 20 feições para o segundo cenário (Figura 8), referente a uma área de $0,15 \mathrm{~km}^{2}$ (1,25\% da área total). Esta redução pode estar relacionada às alterações antrópicas, como o aterramento das feições erosivas iniciais para a realização do nivelamento do relevo, a pavimentação e a implantação de loteamentos.

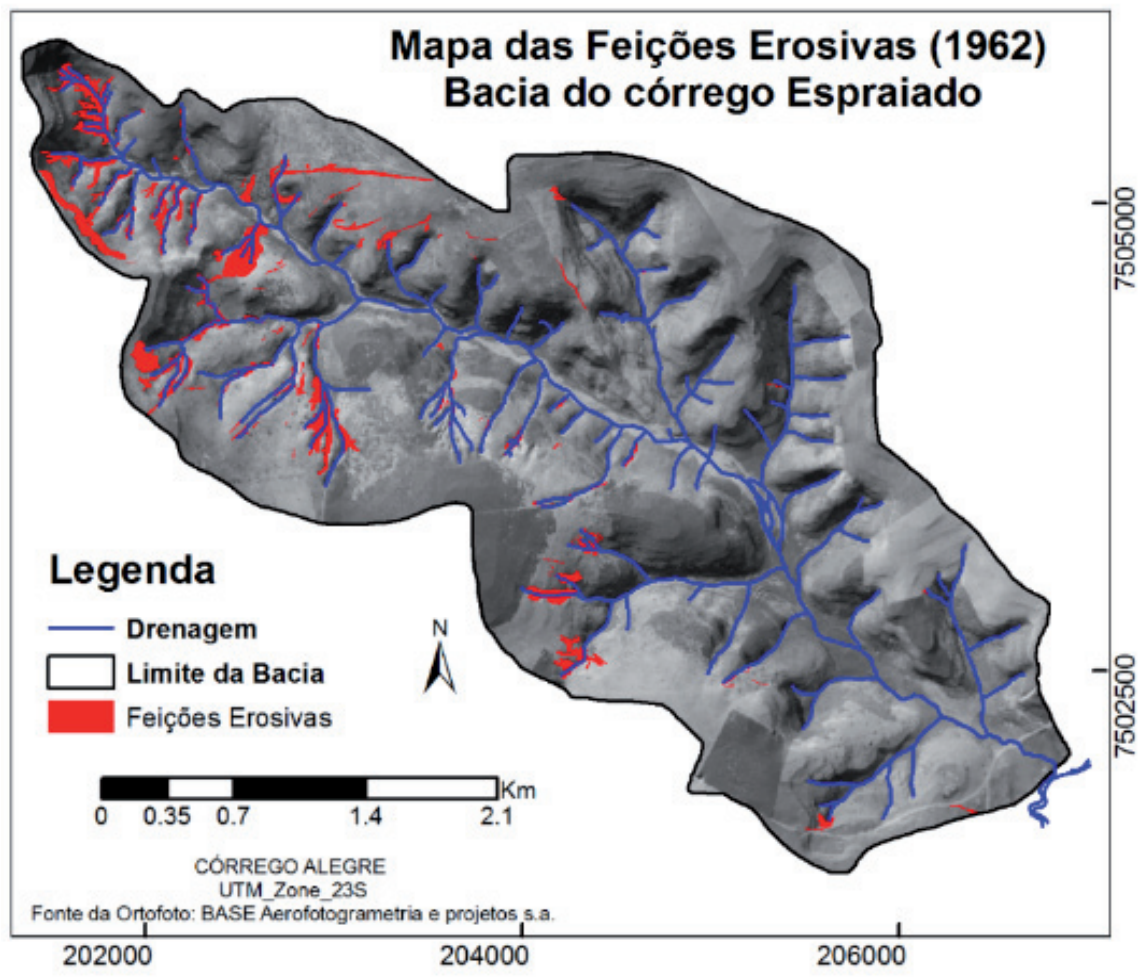

Figura 7 - Mapa das feições erosivas do cenário de 1962. 
Embora Coutard et al. (1978) expliquem que a criação de gado, o desmatamento, a construção de estradas ou caminho são fatores determinantes para o aumento do escoamento superficial e o desenvolvimento das feições, bandlands nas cabeceiras da zona dissecada próxima ao vale do rio Piracicaba. Igualmente como relatado por Lohmann e Santos (2005), em estudos no Rio Grande do Sul, o manejo inadequado pode provocar o desequilíbrio entre a infiltração e o escoamento superficial e consequentemente ativar os processos erosivos.

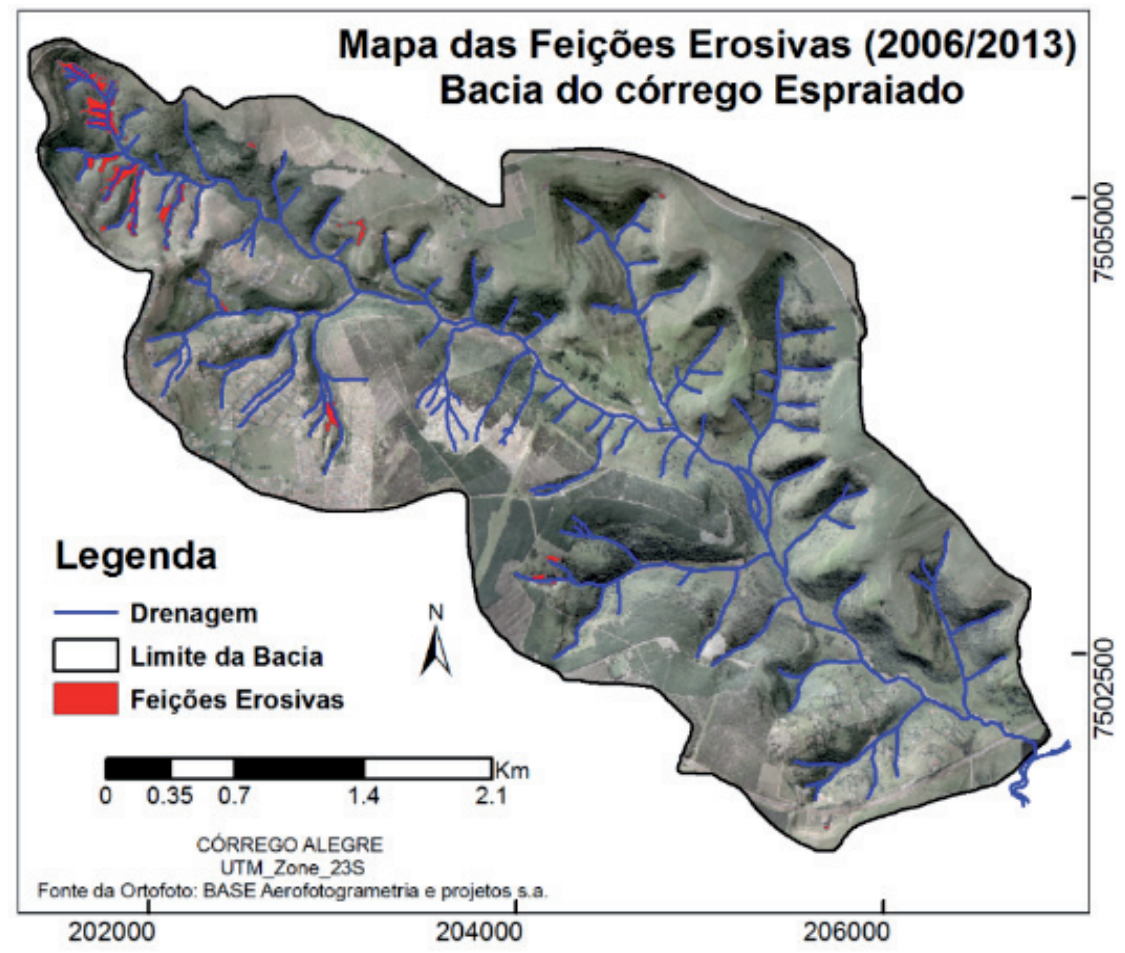

Figura 8 - Mapa das feições erosivas do cenário de 2006.

Em relação à área $\left(\mathrm{m}^{2}\right)$ específica das feições erosivas, ocorreu um aumento significativo de um cenário a outro. No cenário de 1962 variou entre $64 \mathrm{~m}^{2}$ e $49.163 \mathrm{~m}^{2}$, sendo 55\% das feições maior (47 do total de 86) que $1.000 \mathrm{~m}^{2}$, localizadas em áreas de solo exposto e pastagens (Tabela 1). 
Tabela 1 - Número de feições erosivas e suas respectivas áreas $\left(\mathrm{m}^{2}\right)$ do cenário de 1962.

\begin{tabular}{|c|c|}
\hline $\begin{array}{c}\mathrm{N}^{\mathrm{o}} \text { de } \\
\text { Polígonos }\end{array}$ & Área $\left(\mathrm{m}^{2}\right)$ \\
\hline 1 & 64,32 \\
\hline 2 & 65,59 \\
\hline 3 & 66,48 \\
\hline 4 & 66,61 \\
\hline 5 & 67,82 \\
\hline 6 & 85,03 \\
\hline 7 & 100,64 \\
\hline 8 & 125,89 \\
\hline 9 & 126,41 \\
\hline 10 & 128,38 \\
\hline 11 & 165,21 \\
\hline 12 & 182,35 \\
\hline 13 & 210,54 \\
\hline 14 & 234,23 \\
\hline 15 & 268,86 \\
\hline 16 & 291,67 \\
\hline 17 & 307,35 \\
\hline 18 & 310,52 \\
\hline 19 & 323,01 \\
\hline 20 & 331,38 \\
\hline 21 & 342,51 \\
\hline 22 & 361,39 \\
\hline 23 & 373,81 \\
\hline 24 & 388,05 \\
\hline 25 & 472,42 \\
\hline 26 & 497,58 \\
\hline 27 & 505,90 \\
\hline 28 & 539,01 \\
\hline 29 & 620,57 \\
\hline 30 & 626,83 \\
\hline
\end{tabular}

\begin{tabular}{|c|c|}
\hline $\begin{array}{c}\mathrm{N}^{\mathrm{o}} \text { de } \\
\text { Polígonos }\end{array}$ & Área $\left(\mathrm{m}^{2}\right)$ \\
\hline 31 & 639,67 \\
\hline 32 & 684,45 \\
\hline 33 & 709,45 \\
\hline 34 & 716,20 \\
\hline 35 & 753,95 \\
\hline 36 & 785,00 \\
\hline 37 & 970,93 \\
\hline 38 & 971,26 \\
\hline 39 & 990,37 \\
\hline 40 & $1.014,67$ \\
\hline 41 & $1.046,04$ \\
\hline 42 & $1.084,88$ \\
\hline 43 & $1.131,60$ \\
\hline 44 & $1.183,95$ \\
\hline 45 & $1.192,47$ \\
\hline 46 & $1.279,25$ \\
\hline 47 & $1.448,46$ \\
\hline 48 & $1.508,86$ \\
\hline 49 & $1.557,17$ \\
\hline 50 & $1.781,96$ \\
\hline 51 & $1.807,11$ \\
\hline 52 & $1.991,75$ \\
\hline 53 & $2.043,29$ \\
\hline 54 & $2.259,92$ \\
\hline 55 & $2.479,27$ \\
\hline 56 & $2.652,73$ \\
\hline 57 & $2.854,90$ \\
\hline 58 & $3.517,33$ \\
\hline 59 & $3.580,34$ \\
\hline 60 & $3.628,85$ \\
\hline
\end{tabular}

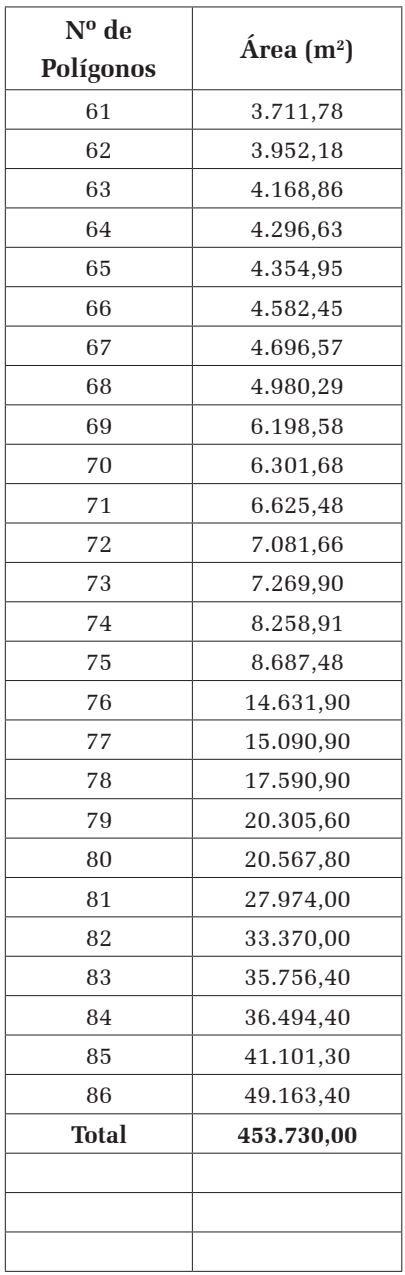

Em um trabalho na mesma área, Yamanouth (2003) mapeou as feições erosivas do cenário de 1972, atribuindo uma classificação e simbologia para os 50 polígonos de feições erosivas: concentração de sulcos (C), ravinas (R), voçorocas (V) e concentração de sulcos e ravinas (CR). A autora verificou a menor feição com $1.161 \mathrm{~m}^{2}$ e a maior $92.386 \mathrm{~m}^{2}$, totalizando uma área de $0,87 \mathrm{~km}^{2}$, equivalente a 7,3\% da área total. Essa diferença pode estar relacionada à precisão geométrica dos mapas além 
da interpretação e dos critérios adotados, uma vez que a autora considerou os sulcos, as ravinas e as voçorocas. No cenário de 2006, o valor mínimo encontrado foi $328 \mathrm{~m}^{2}$ e o máximo $48.598 \mathrm{~m}^{2}$, sendo $70 \%$ (14 do total de 22) das feições maiores que $1000 \mathrm{~m}^{2}$, que podem estar relacionadas ao aumento do escoamento pluvial decorrente da impermeabilização do solo e do uso destinado à urbanização (Figura 9 e Tabela 2).

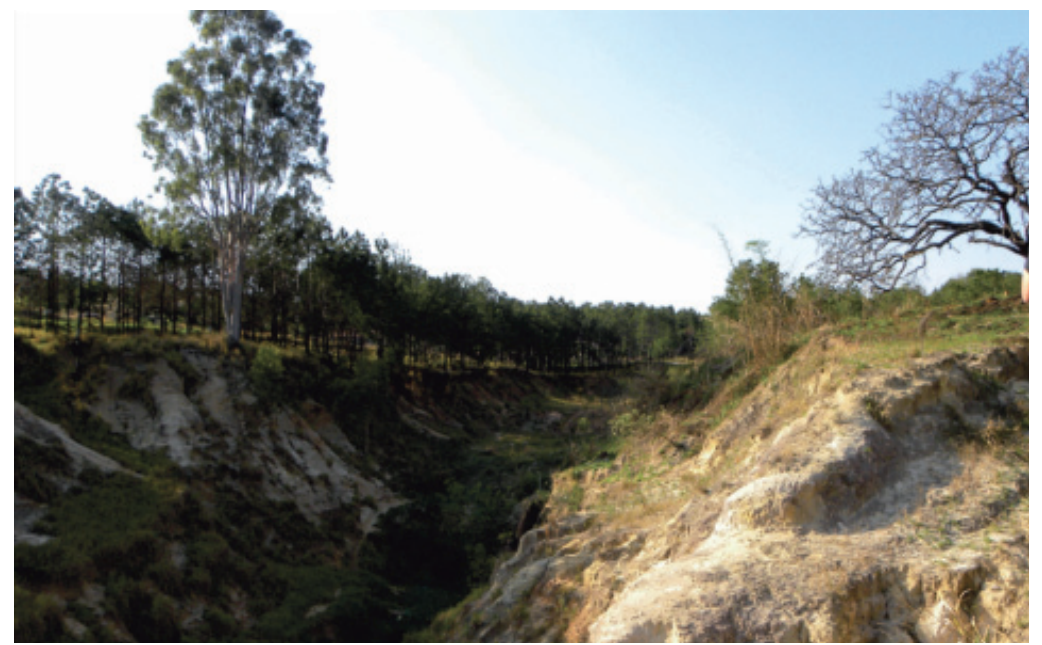

Figura 9 - Feição erosiva com taludes acentuados e profundos. No seu interior, verifica-se a presença significativa de solo exposto e de graus demonstrando ainda sua evolução. Ano 2013.

Tabela 2 - Número de feições erosivas mapeadas e as respectivas áreas $\left(\mathrm{m}^{2}\right)$ do cenário de 2006.

\begin{tabular}{|c|c|}
\hline $\mathbf{N}^{\mathbf{0}}$ de Polígonos & Área $\mathbf{( m}^{\mathbf{}} \mathbf{~}$ \\
\hline 1 & 328,31 \\
\hline 2 & 335,30 \\
\hline 3 & 419,46 \\
\hline 4 & 550,26 \\
\hline 5 & 832,58 \\
\hline 6 & 838,05 \\
\hline 7 & $1.057,72$ \\
\hline 8 & $1.183,76$ \\
\hline 9 & $1.475,54$ \\
\hline 10 & $1.698,89$ \\
\hline 11 & $2.965,39$ \\
\hline
\end{tabular}

\begin{tabular}{|c|c|}
\hline $\mathbf{N}^{\mathbf{0}}$ de Polígonos & Área $\mathbf{( m}^{\mathbf{}} \mathbf{)}$ \\
\hline 12 & $4.638,85$ \\
\hline 13 & $6.281,46$ \\
\hline 14 & $7.560,82$ \\
\hline 15 & $9.757,39$ \\
\hline 16 & $10.069,67$ \\
\hline 17 & $14.966,95$ \\
\hline 18 & $15.421,99$ \\
\hline 19 & $17.921,51$ \\
\hline 20 & $48.598,93$ \\
\hline Total & $\mathbf{1 4 7 . 0 0 0}$ \\
\hline & \\
\hline
\end{tabular}


Considerando o número e a área total das feições erosivas de ambos os cenários, além das observações in loco (com profundidade média $9,72 \mathrm{~m})$, foi calculado o volume $\left(\mathrm{m}^{3}\right)$ de perda de solo, sendo o maior valor registrado no cenário de $1962\left(4.410 .000 \mathrm{~m}^{3}\right)$, com uma diferença superior de aproximadamente de 300\% em relação ao cenário de 2006 (1.428.000 $\mathrm{m}^{3}$ ). Esse resultado pode ser atribuído ao maior número de feições erosivas e, portanto, a maior susceptibilidade erosiva para o cenário de 1962 (Figura 10). Tal situação também possibilitou analisar empiricamente a magnitude das feições e o tamanho da área, além da localização delas em cabeceiras de afluentes, principalmente na média bacia.
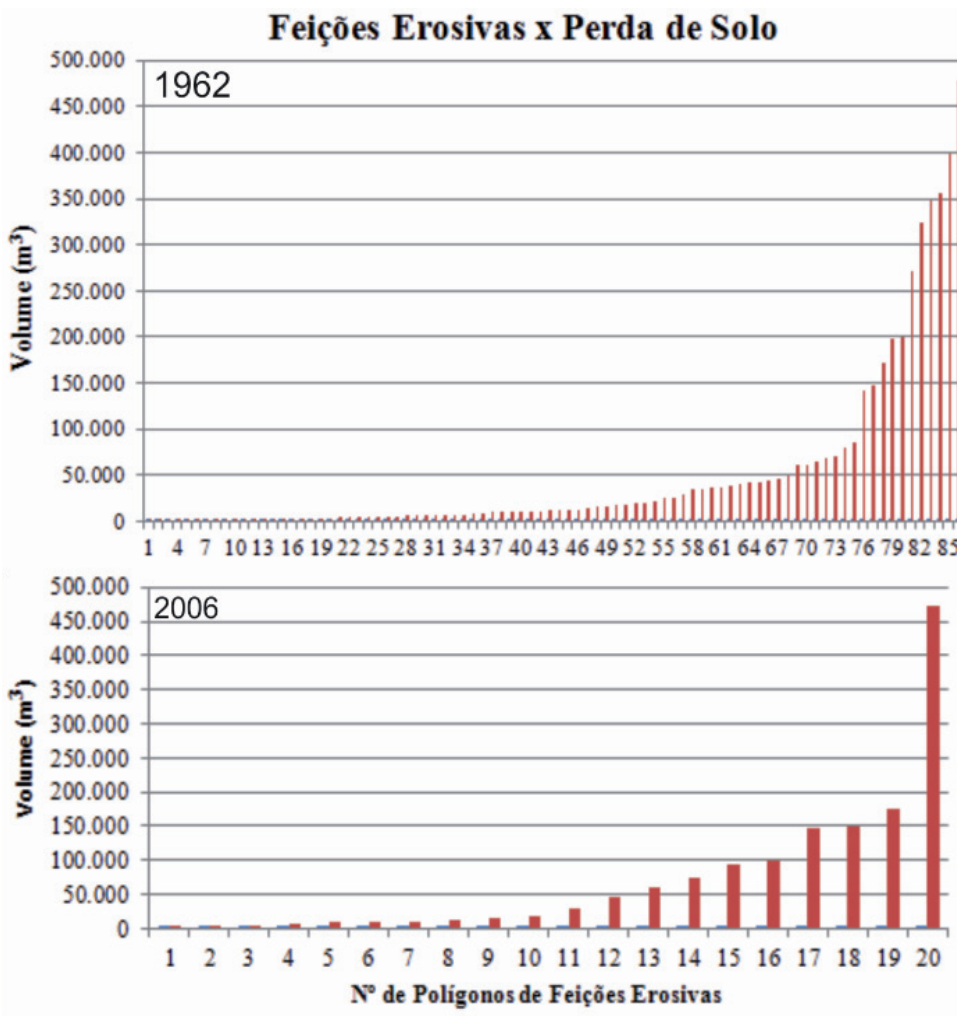

Figura 10 - Perda de solo em volume $\left(\mathrm{m}^{3}\right)$ das feições erosivas mapeadas nos cenários de 1962 e de 2006. 
Carpi Junior (1996) identificou, por meio da elaboração e da aplicação de técnicas cartográficas em uma bacia próxima, que as zonas de cabeceiras na alta e média bacia, possuem maior susceptibilidade principalmente de processos erosivos lineares acelerados. Essas são áreas de concentração de fluxos e de detritos devido a maior presença de áreas côncavas, maior fragilidade litológica, e, portanto, maior capacidade erosiva (Kirkby; Chorley, 1967).

\section{Distribuição espacial das feições}

Em ambos os cenários, a maior ocorrência das feições erosivas foram registradas nos setores da alta e média bacia e, sobretudo na margem direita (Figura 11). As feições do setor da alta bacia provavelmente estão relacionadas com a ruptura de declive, à proximidade da rocha junto à superfície e à presença de colúvios arenosos pouco espessos, conforme apontam também Coutard et al. (1978). Nesta área, Furquim (2002) classificou o material como Neossolo Litólico e Gleissolo, com cerca de $60 \mathrm{~cm}$, pouco desenvolvido e limite abrupto entre o horizonte A (mais poroso) e o horizonte $\mathrm{C}$ (menos poroso) e semelhante à rocha sã. Provavelmente tal fato contribuiu para a rápida saturação do solo, devido à baixa capacidade de infiltração e, consequentemente à formação do escoamento superficial de alto poder erosivo.

A susceptibilidade das zonas de cabeceiras tanto do canal principal como as áreas circundantes dos canais de primeira e segunda ordens, também pode estar associado ao relevo dissecado, aos vales encaixados, as maiores declividades (10 - 20\%), além da forte presença de curvaturas côncavas. Outros autores também identificaram a ocorrência de feições erosivas em cabeceiras, tais como: Dias Ferreira (1997), na região de São Pedro (SP), observou que os sulcos, as ravinas e as voçorocas se desenvolvem em quase todas as cabeceiras de drenagem. Situação semelhante encontrada por Oliveira (1997) e Araújo (2011) também na região de São Pedro (SP), por Salomão (1994) em Bauru (SP), por Salgado et al. (2008) no interior do estado do Rio de Janeiro (RJ) e por Santana et al. (2007) no sudoeste de Goiás (GO). 


\section{Mapa das Feições Erosivas (1962 e 2006/2013)} Bacia do Córrego Espraiado

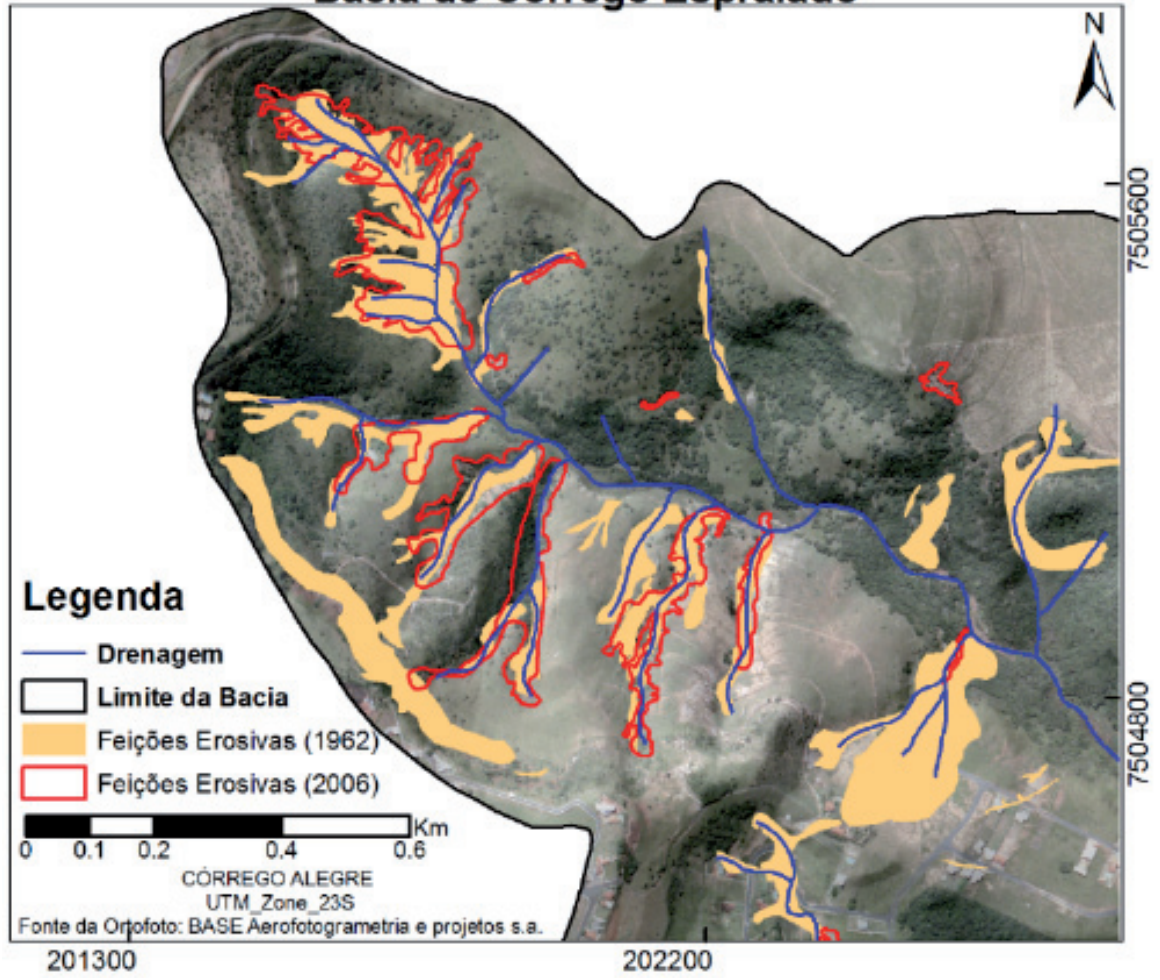

Figura 11 - Trecho da cabeceira da bacia mostrando as feições erosivas de 1962 e de 2006.

Silva (2003) afirmou que as feições erosivas lineares numa determinada bacia no município de São Pedro (SP) estão relacionadas com a concentração de fluxo de águas pluviais nas cabeceiras da drenagem. Entretanto, a declividade encontrada pelo autor neste setor variou entre $10 \%$ e $50 \%$, diferentemente ao intervalo encontrado nesta pesquisa (20 - 40\%). Ainda o mesmo autor explica que a alta declividade facilita o escoamento superficial e a remoção consequente do material inconsolidado, extremamente arenoso com variações granulométricas de média a fina, porosidades em torno de 40\%, valores relativamente elevados dos índices de vazios e baixa taxa de resistência à erosão. 
Em direção à jusante da bacia observou-se de forma geral uma redução significativa do volume das feições erosivas em ambos os cenários, o que pode estar relacionada à diminuição da energia da água, à redução da declividade média e a maior presença de Neossolos Quartzarênico e Neossolos Quartzarênico com bandas, que possuem maior profundidade e maior capacidade de infiltração e, portanto, menor escoamento, conforme apontado por Furquim (2002).

\section{Considerações finais}

A variedade de feições e suas irregularidades indicaram uma grande complexidade de feições erosivas, que pode estar associada, provavelmente, aos mecanismos de formação e de desenvolvimento, tais como: fluxos superficiais e subsuperficiais e intensa atividade pecuária. Destaca-se, também, que nas áreas das cabeceiras de drenagens foram registrados os maiores números de feições erosivas em ambos os cenários (1962 e 2006). Tal fato está associada a própria dinâmica evolutiva do relevo das cuestas, sobretudo em encostas com formas côncavas, declividades entre $20 \%$ e $40 \%$ solo pouco espessos.

Sobre o método aplicado, ressalta-se que, atualmente, com a melhor resolução do material cartográfico, especialmente das fotografias aéreas e a detalhada validação em campo de todas as feições erosivas foram fundamentais para a delimitação da área, da forma e do volume de perda do solo. Desta forma, foi possível verificar que grande parte do solo exposto ainda na década de 1960 foi substituída em parte por atividades da pecuária e silvicultura e por implementação de sítios urbanos. Esta última promoveu uma impermeabilização de parte da bacia, aumentando o escoamento superficial e deflagrando novas feições erosivas.

\section{Nota}

1. Mosaico obtido das fotografias aéreas. Fontes: Instituto Agronômico de Campinas (IAC), Instituto de Pesquisas Tecnológicas do Estado de São Paulo (IPT) e Base Aerofotogrametria, S.A. 


\section{Agradecimentos}

Os autores agradecem o apoio financeiro do CNPq, por meio do Projeto 480515/2011-5 (Edital/Chamada: Universal 14/2011), e pela bolsa de estudo. Os autores agradecem aos seus colegas pelo apoio, discussão e revisão: Profa. Dra. Lylian Zulma Doris Coltrinari, Prof. Dr. Adilson Avansi de Abreu, Prof. Dr. Leonardo José Cordeiro Santos, doutorando Tiago D. Martins, Rogério Vieira Gomes, Marcos Roberto Pinheiro e Clementino Antonio Daniel. Este artigo recebeu contribuições significativas dos revisores anônimos.

\section{Referências}

AB’SABER, A. N. Regiões de circundesnudação pós-cretácea, no planalto brasileiro. Boletim de Geografia, São Paulo, n. 1, p. 3-21, 1949.

ALARSA, C. Estudo das associações entre as formas de relevo e os solos do interflúvio dos Ribeirões Samambaia e Araquá, na Região de Águas de São Pedro $(S P)$. Trabalho de Conclusão de Curso. Departamento de Geografia. Faculdade de Filosofia Letras e Ciências Humanas, USP, São Paulo, 1994.

ARAUJO, T. P. Estudo do desencadeamento das erosões lineares concentradas em uma área do município de São Pedro (SP). Dissertação (Mestrado em Geotecnia) Escola de Engenharia de São Carlos, USP, São Carlos, 2011.

BASE, S. A. Fotografias aéreas do município de São Pedro (SP). Escala 1:25.000, 1962. VW AST - 10; 1370OPMW R - 306. Faixas 2435 e 2436.

. Fotografias aéreas do município de São Pedro. Escala 1:30.000. Abril/2006. $\overline{\mathrm{B}}-\overline{\mathrm{O}} \overline{9} \overline{1} \overline{7}$. Faixa: 132 n. 5960, 5961, 5962, 5963, 5964, 5965, 5966. Faixa: 131 n. 3777 e 3778 .

BERTONI, J.; LOMBARDI NETO, F. Conservação do solo. 2. ed. Piracicaba, SP: Livroceres, 1985.

BÓSIO, N. J. Geologia da área de São Pedro (SP). Tese (Doutorado) - Faculdade de Filosofia, Letras e Ciências Humanas, USP, São Paulo, 1973.

BRAIMOH, A. K.; VLEK, P. L. G. Impact of land use on soil resources. In: BRAIMOH, A. K.; VLEK, P. L. G (Orgs.). Land use and soil resources. Springer: Sweden, 2007. p. 1-8.

BRADY, N. C. Natureza e propriedades dos solos. Rio de Janeiro: Freitas Bastos, 1989.

CÂMARA, G.; MEDEIROS, J. S. Geoprocessamento para projetos ambientais. In: CÂMARA, G.; DAVIS, C.; MONTEIRO, A. M. V. (Orgs.). Introdução à ciência da geoinformação. São José dos Campos, SP: INPE, 2001, cap. 10. p. 1-36. Disponível em: <www.dpi.inpe.br/gilberto/livro/introd/cap10-aplicacoesambientais.pdf>. Acesso em: 21 fev. 2011.

CARPI JUNIOR, S. Técnicas cartográficas aplicadas à dinâmica da bacia do ribeirão Araquá (SP). Dissertação (Mestrado em Organização do Espaço) - 
Instituto de Geociências e Ciências Exatas, Universidade Estadual Paulista, Rio Claro, 1996.

CHRISTOFOLETTI, A. Geomorfologia. São Paulo: Edgard Blucher, 1980.

COLTRINARI, L. Geomorfologia: caminhos e perspectivas. Revista Brasileira de Geomorfologia, v. 1, n. 1, p. 44-47, 2000.

COUTARD, J. P.; DIAS FERREIRA, R. P.; PELLERIN, J., QUEIROZ NETO, J. P. Excursão à região da serra de São Pedro e vale do rio Piracicaba. Guia de Excursões. In: Colóquio Interdisciplinar Franco-Brasileiro: Estudo e Cartografação de Formações Superficiais e suas Aplicações em Regiões TropicaiS. Faculdade de Filosofia, Letras e Ciências Humanas, Universidade de São Paulo, São Paulo, 1978.

CRUZ, O. A. Escala temporal-espacial nos estudos dos processos geomorfológicos erosivos atuais: uma questão de método. Geomorfologia, Instituto de Geografia, USP, São Paulo, n. 33, p. 1-6, 1985.

DAEE. Controle de erosão: bases conceituais e técnicas: diretrizes para o planejamento urbano e regional - orientações para o controle de boçorocas urbanas. São Paulo: DAEE/IPT, 1989.

DIAS FERREIRA, R. P. Solos e morfogênese em São Pedro (SP). Tese (Doutorado) - Faculdade de Filosofia, Letras e Ciências Humanas, Universidade de São Paulo, São Paulo, 1997.

EMBRAPA. Empresa Brasileira de Pesquisas Agropecuárias. Sistema brasileiro de classificação de solos. 3. ed. Brasília, 2013.

FURQUIM, S. A. C. Interações entre modelo e solo no transecto do Espraiado, São Pedro/SP. Dissertação (Mestrado) - Departamento de Geografia, Faculdade de Filosofia, Letras e Ciências Humanas, Universidade de São Paulo, São Paulo, 2002.

GOUDIE, A. Geomorphological techniques. London: Routledge, 1990.

KERTZMAN, F. F.; OLIVEIRA, A. M.; SALOMÃO, F. X.; GOUVEIA, M. I. F. Mapa da erosão no estado de São Paulo. Revista do Instituto Geológico, São Paulo, volume especial, p. 31-36, 1995.

KIRKBY, M. J.; CHORLEY, R. J. Throughflow, overland flow and erosion. Bulletin of the International Association of Scientific Hydrology, v. 12, n. 3, p. 5-21, 1967.

KUHNERT, P. M.; HENDERSON, A.K.; BARTLEY, R.; HERR, A. Incorporating uncertainty in gully erosion calculations using the random forests modelling approach. Journal Article, Environmetrics, v. 21, p. 493-509, 2010.

LOHMANN, M.; SANTOS, L. J. C. A morfopedologia aplicada à compreensão dos processos erosivos na bacia hidrográfica do Arroio Guassupi, São Pedro do Sul, RS. Revista Brasileira de Geomorfologia, ano 6, n. 2, p. 91-102, 2005.

MACEDO, E. S.; OGURA; A. T.; KATIA, C.; ALMEIDA FILHO. G. S.; GRAMANI, M. F.; SILVA, F. C.; CORSI, A. C.; MIRANDOLA, F. A. Modelos de fichas descritivas para áreas de risco de escorregamento, inundação e erosão. In: SIMPÓSIO BRASILEIRO DE DESASTRES NATURAIS, Florianópolis: GEDN/UFSC, 2004. 
MAURO, C. A. Voçorocas: marcas das relações sociedade-natureza na bacia do Monjolinho, São Carlos (SP). Tese (Doutorado) - Faculdade de Filosofia, Letras e Ciências Humanas, Universidade de São Paulo, São Paulo, 1989.

MENDONÇA, J. K. S.; GUERRA, A. J. T.; MENDES, M. R. Diagnóstico da erosão urbana no município de São Luís (MA). In: VII SIMPÓSIO NACIONAL DE CONTROLE DE EROSÃO, Goiânia, 2001.

MONTGOMERY, D. R. Dirt: the erosion of civilization. Berkeley: University of California Press, 2008.

OLIVEIRA, M. A. Inventário histórico das formas de erosão linear no interflúvio entre os ribeirões do Meio e Samambaia no glacis de São Pedro (SP). Trabalho de Conclusão de Curso. Departamento de Geografia, Faculdade de Filosofia, Letras e Ciências Humanas, Universidade de São Paulo, São Paulo, 1997.

RISER, J. Erosão e paisagens naturais. Lisboa: Flammarion, 1995.

SALGADO, C. M.; SILVA, T. P.; PEIXOTO, M. N. O.; MOURA, J. R. S. Análise espaçotemporal da erosão linear no médio baixo vale do ribeirão do secretário Paty do Alferes/RJ. Revista Brasileira de Geomorfologia, v. 9, n. 1, p. 75-85, 2008.

SALOMÃO, F. X. T. Processos erosivos em Bauru (SP): regionalização cartográfica aplicada ao controle preventivo urbano e rural. Tese (Doutorado em Geografia Física) - Faculdade de Filosofia, Letras e Ciências Humanas, Universidade de São Paulo, São Paulo, 1994.

SANCHEZ, M. C. Contribuição ao conhecimento das bases naturais dos municípios de São Pedro e Charqueada (SP). Notícia Geomorfológica, Campinas, v. 11, n. 21-22, p. 47-60, 1971.

SANTANA, N. M. P.; CASTRO, S. S.; STONE, L. F.; SILVA, S. C. Chuvas, erosividade, erodibilidade, uso do solo e suas relações com focos erosivos lineares na alta bacia do rio Araguaia. Sociedade e Natureza, Uberlândia, v. 19, n. 2, p. 103121, 2007.

SANTORO, J.; FULFARO, V. J. Estudos geotécnicos em boçoroca na cidade de São Pedro, São Paulo (SP). Revista do Instituto Geológico, São Paulo, v. 17, n. 1-2, p. 55-62, 1996.

SIDORCHUK, A. Dynamic and staticmodelsofgully erosion. Catena, n. 37, p. 401414, 1999.

SILVA, L. C. F. Fotointerpretação de redes de drenagem e caracterização do relevo de dois solos do município de São Pedro (SP). Tese (Doutorado em Solos e Nutrição de Plantas) - Escola Superior de Agricultura, Universidade de São Paulo, Piracicaba, 1993.

SILVA, A. F. Mapeamento geotécnico e análise dos processos erosivos na Bacia do Córrego Tucum - São Pedro (SP), Escala 1:10.000. Dissertação (Mestrado em Geotecnia) - Escola de Engenharia de São Carlos, Universidade de São Paulo, São Carlos, 2003.

TAMENE, L.; VLEK, P. L. G. Soil erosion studies in Northern Ethiopia. In: BRAIMOH, A. K.; VLEK, P. L. G (Orgs.). Land use and soil resources. Springer: Sweden, 2007. p. 73-100. 
TORRI, D. Slope, aspect and surface storage. In: AGASSI, M. (Org.). Soil erosion, conservation e rehabilitation. Israel: Ministry of Agriculture Emek-Hefer, cap. 5, 1996. p. 77-106.

YAMANOUTH, G. R. de B. Avaliação dos processos erosivos e das técnicas de controle e reabilitação: bacia do córrego do Espraiado - São Pedro (SP). Dissertação (Mestrado em Geotecnia) - Escola de Engenharia de São Carlos, Universidade de São Paulo, São Carlos, 2003.

VEIGA, T. C.; SILVA. J. X. Geoprocessamento aplicado à identificação de áreas potenciais para atividades turísticas: o caso do município de Macaé (RJ). In: SILVA, J. X.; ZAIDAN, R. T. (Orgs.). Geoprocessamento e análise ambiental: aplicações. Rio de Janeiro: Bertrand Brasil, 2004. p. 179-215.

ZUQUETTE, L. V.; CARVALHO, J. A. R.; YAMANOUTH, G. R. B. Feições erosivas na bacia do córrego do Espraiado, São Pedro (SP), seus tipos e evolução entre 1972-2002. Revista Brasileira de Geociências, v. 2, n. 37, p. 414-425, 2007.

Evandro Daniel - Possui Bacharelado e Licenciatura em Geografia pela Universidade Estadual Paulista Júlio de Mesquita Filho. Mestrado em Geografia pela Universidade de São Paulo.

Bianca Carvalho Vieira - Possui Bacharelado e Licenciatura em Geografia pela Universidade Federal do Rio de Janeiro. Mestrado e Doutorado em Organização e Gestão Ambiental pela mesma Universidade. Atualmente é professora na Universidade de São Paulo.

Recebido para publicação em 30 de abril de 2015

Aceito para publicação em 3 de junho de 2015 